\title{
LAS CADENAS PRODUCTIVAS COMO FUENTE DE OPORTUNIDADES PARA EMPRENDEDORES EN EL MEDIO RURAL
}

Esteban Campero ${ }^{1}$

${ }^{1}$ Jefe de Investigación, Fundación Redes del Conocimiento Profesor titular, Maestría en Economía Agroalimentaria Universidad Nacional de La Plata, Buenos Aires, Argentina Correo electrónico: ecampero@uplata.edu.ar

Recibido: 18 de enero del 2015. Aprobado: 27 de abril del 2015.

Cómo citar este artículo: E. Campero. "Las cadenas productivas como fuente de oportunidades para emprendedores en el medio rural”. Ingeniería Solidaria, vol. 11, n. ${ }^{0}$ 18, pp. 75-85, ene.-dic. 2015. doi: http://dx.doi.org/10.16925/in.v11i18.993

Resumen. Este artículo de reflexión no derivado de investigación analiza cómo los programas de apoyo a emprendedores adquieren cada vez más importancia para Gobiernos, universidades y organizaciones, partiendo de la existencia de una correlación positiva entre crecimiento económico y creación de empresas. El campo y los agronegocios son un área muy competitiva en muchos países de Sudamérica, los cuales no suelen contar con un abordaje particular en materia emprendedora, teniendo en cuenta las características diferenciadoras del medio rural. Aquí se analiza cómo las cadenas productivas locales son una importante fuente de oportunidades para emprendedores que merecen un abordaje más acabado ya que permiten que las acciones de fortalecimiento del sector productivo no sean aisladas $y$, por lo tanto, mejoren sus oportunidades de éxito u optimicen su efecto. Si bien es el emprendedor el que identifica las oportunidades, las cadenas pueden ser un buen espacio para hacerlo y los programas de apoyo deberán prestarle especial atención. La importancia de las cadenas productivas a un proceso de desarrollo emprendedor radica, entre otras razones, en que permite conocer cada dimensión de la actividad económica de las localidades e identificar oportunidades a partir de estas.

Palabras clave: agronegocios, cadenas productivas, clúster, desarrollo local, emprendedores, innovación. 


\title{
Productive Chains as a Source of Opportunities FOr ENTREPRENEURS in THE RURAL SPHERE
}

\begin{abstract}
This article of reflection not derived from research analyzes how support programs for entrepreneurs acquire increasingly greater importance for governments, universities and organizations, beginning with the existence of a positive correlation between economic growth and the creation of companies. The countryside and agribusinesses are a very competitive area in many South American countries, which do not generally have a particular approach in the field of entrepreneurship, taking into account the differentiating characteristics of the rural sphere. This article analyzes how local productive chains are an important source of opportunities for entrepreneurs, which merit a closer look because such chains make it possible to avoid taking actions to strengthen the productive sector in isolation and, on the contrary, to improve their opportunities for success or optimize their effects. While it is the entrepreneurs themselves who identify opportunities, the productive chains can be a good venue for doing so and support programs should pay special attention to them. The importance of productive chains in an entrepreneurial development process stems, among other reasons, from the fact that they facilitate knowledge of each dimension of economic activity in localities and identify opportunities based on them.
\end{abstract}

Keywords: agribusinesses, productive change, clúster, local development, entrepreneurs, innovation.

\section{AS CADEIAS PRODUTIVAS COMO FONTE DE OPORTUNIDADES PARA EMPREENDEDORES NO MEIO RURAL}

Resumo. Este artigo de reflexão não derivado de pesquisa analisa como os programas de apoio a empreendedores adquirem cada vez mais importância para Governos, universidades e organizações, partindo da existência de uma correlação positiva entre crescimento econômico e criação de empresas. O campo e os agronegócios são uma área muito competitiva em muitos países da América do Sul, os quais não costumam contar com uma abordagem particular em matéria empreendedora, que leve em consideração as características diferenciadoras do meio rural. Analisam-se como as cadeias produtivas locais são uma importante fonte de oportunidades para empreendedores que merecem uma abordagem mais acabada já que permitem que as ações de fortalecimento do setor produtivo não sejam analisadas e, portanto, melhorem suas oportunidades de sucesso ou otimizem seu efeito. Embora seja o empreendedor o que identifica as oportunidades, as cadeias podem ser um bom espaço para fazê-lo e os programas de apoio deverão prestar atenção. A importância das cadeias produtivas a um processo de desenvolvimento empreendedor radica, entre outras razões, em que permite conhecer cada dimensão da atividade econômica das localidades e identificar oportunidades a partir delas.

Palavras-chave: agronegócios, cadeias produtivas, clúster, desenvolvimento local, empreendedores, inovação. 


\section{Introducción}

Los cambios generados por la globalización hacen más dependientes las economías y exigen de ellas mayores niveles de competitividad, con el fin de ganar mercados. El logro de la competitividad ya no es exclusividad de una sola empresa, sino del sector en el cual se desarrolla la actividad y las condiciones que un país o una región brindan para que sus sectores productivos estén en capacidad de competir en el mercado. Una de las grandes paradojas de la actual economía global es el hecho de que cada vez más ventajas competitivas duraderas tienen que ver con factores locales, con determinados condicionantes ubicados en ciertos espacios geográficos (tales como el conocimiento, la cultura colectiva, las relaciones y la motivación), los cuales los rivales distantes no pueden igualar. Las empresas ya no compiten por sí solas sino a partir del entorno productivo del que forman parte. Es a partir de aquí que se revaloriza el papel de los sistemas productivos locales.

Otra característica fundamental del nuevo desarrollo económico es la necesidad de fomentar la creación de nuevas empresas. Por lo general, se solía ligar el desarrollo económico con la generación de estructuras empresariales más grandes, complejas y jerarquizadas. Estudios de casos de éxito tales como la industria japonesa, italiana, irlandesa y de otros países, abrieron paso a querer estudiar realidades de crecimiento con una estructura muy diferente. Tal como lo demuestran innumerables estudios, es posible decir que en la inmensa mayoría de los países, tanto los desarrollados como los emergentes, las nuevas empresas cumplen un rol fundamental. Suelen generar más empleo que las más grandes y ser empresas innovadoras, así como ser más resistentes a los cambios y se suelen ajustar mejor ante los nuevos escenarios. De allí la importancia de fomentar su nacimiento. Fomentar la creación de empresas depende de una articulación acertada de los diversos actores de las localidades, entre los que se distinguen las empresas y su red de proveedores y clientes, el sector público con sus programas de apoyo y su marco legal, el sistema educativo y las pautas culturales. Diversos investigadores del desarrollo emprendedor como Kantis [1], adaptan la noción de sistemas productivos locales con el fin de hablar de sistemas de desarrollo emprendedor.

Según esta mirada, en el interior del proceso emprendedor se producen distintos elementos de "salida" (output), los cuales son los emprendedores y las empresas, empujados por tres elementos claves como la gestación del proyecto, el lanzamiento de la empresa y su desarrollo inicial, todos estos condicionados por un conjunto de elementos y factores tales como la cultura, las condiciones sociales y económicas, el sistema educativo, la estructura y dinámica productiva, y el sistema educativo. Un análisis pormenorizado también demuestra el peso específico que produce la construcción de redes sociales y el perfil personal del emprendedor. Sin embargo, la dinámica del proceso emprendedor adquiere diferentes características en las diversas localidades, generando disparidades en sus resultados siempre condicionados por la articulación de sus actores.

En este mundo globalizado, los niveles de competencia se hacen más exigentes, de manera que es necesario empezar a trabajar a nivel de una competencia entre cadenas productivas, con el fin de lograr un desarrollo del sector agropecuario. El importante grado de tecnificación y desarrollo de gran parte del sector de los últimos años se debe, entre otras cosas, a la importante aparición de servicios a la industria agropecuaria y a su encadenamiento productivo, en el cual distintas empresas desarrollan diferentes fases de producción para llegar a la elaboración de un producto final. Se estima que en la mayoría de las industrias sólo el treinta por ciento de las empresas llega al cliente final, dedicándose la mayoría a alimentar estas cadenas. No obstante, la situación actual de muchas regiones del ámbito rural demuestra una falta de integración entre los agentes, los cuales, por el contrario, compiten individualmente entre sí (proveedores de insumos, intermediarios, medios de transformación, comercialización, etc.). En otros casos, muchas de estas cadenas se encuentran incompletas, y habitualmente las empresas se ven obligadas a importar parte de los productos y servicios que necesitan para su desarrollo, generando una pérdida de competitividad local importante, aumentando los costos de producción e impidiendo también el desarrollo de un círculo virtuoso. Los sectores productivos y el Estado comienzan a identificar estas características, fomentando la interrelación y la conformación de conglomerados productivos, con el objetivo de enfrentar de alguna manera el análisis convencional del sector rural, el cual pretendía, a través de una visión fragmentada y centrada en el productor, entender el mundo de los negocios agrícolas y su contexto. Queda claro que la producción 
agropecuaria no es una actividad que nace y muere en el establecimiento rural, sino que también se sostiene y alimenta de diversos proveedores y servicios que la sectorizan por rama productiva. La identificación de cuáles son estos servicios y proveedores que están haciendo falta en cada una de las cadenas, puede ser una fuente de identificación de oportunidades para los emprendedores.

Las políticas públicas como otro componente esencial que define el desarrollo del ecosistema emprendedor se proponen, entre otras cosas, brindar apoyo para desarrollar las características emprendedoras personales.

La promoción del desarrollo emprendedor es un objetivo común de la mayoría de los países. Existe una correlación positiva entre la tasa de creación de empresas y el crecimiento económico. Si bien no se conoce con exactitud qué ocurre primero, esto es motivo suficiente para que los programas de apoyo a emprendedores estén presentes en las políticas públicas desde mediados de los ochenta. En una primera instancia, los programas de apoyo a emprendedores buscaban dar respuesta a una Europa en crisis, colapsada por el desempleo y el estancamiento. En este contexto, los emprendimientos ganan escena como protagonistas principales por su capacidad de generar innovaciones y su capacidad de adaptación a los cambios en el escenario económico, apoyados en la creatividad y su fortaleza para potenciar las economías regionales.

Pero el peso que fue adquiriendo el emprendedor en el desarrollo excede a la economía o a las características personales. El fenómeno emprendedor tiene su raíz en un contexto social en el que se desenvuelve. Cada emprendedor se desarrolla a partir de su interacción con el medio, influenciado por su experiencia laboral, estilo de vida, nivel socioeconómico, etc. Diversos estudios sociológicos como el de Etzloni [2] y Thornton [3], se detienen en su aporte a la sociedad en un sentido amplio, asumiendo una función social de adaptar y cambiar patrones sociales ya obsoletos, por patrones más adaptados a una realidad en constante cambio. Según Thornton, los emprendedores son un subgrupo de nuestra sociedad con características bien diferenciadas. Estas características son las que cuesta identificar y abren camino a otro marco de análisis: el de la psicología. Para la sociología, estas características y habilidades varían según un determinado contexto histórico. En el nuevo paradigma tecnoeconómico de la sociedad del conocimiento, por ejemplo, se agudizan las habilidades de generar redes de apoyo, linkear y ser creativo. Pero la pregunta desde la sociología también radica en cómo se promueve la aparición de más emprendedores, y parte de la respuesta se busca en la idea de legitimación social. Con ella nos referimos a un amplio conjunto de valores y costumbres que proveen aprobación moral de actividades específicas. La legitimación influye en todos los aspectos del desarrollo emprendedor, tanto los obstáculos como las preferencias. Para la sociología, las fuentes de legitimación pueden ser el contacto con otras civilizaciones y la difusión de valores, cambio en el liderazgo político y en las elites intelectuales, movimientos sociales y el sistema educativo, clave en todo el proceso. La visión centrada en la persona falla en reconocer que es en el contexto social en el que se determinan las ideas de nuevos emprendimientos.

Definimos competencia como la capacidad de un individuo de ejercer una actividad poniendo en juego la combinación de conocimientos, habilidades y actitudes. Estas competencias, en correlación con el contexto, condicionarán las posibilidades del desarrollo de un emprendimiento. Las competencias se adquieren y se desarrollan en cualquier contexto. Algunas de las competencias son distintivas de los emprendedores y tienen que ver con la capacidad de identificar y aprovechar oportunidades, desarrollar redes de apoyo, trabajar en equipo, asumir riesgos, saber planificar, etc. Todos ellos, saberes tácitos que no suelen ser codificados por la educación formal. Algunos teóricos del desarrollo emprendedor [4] se dedicaron a estudiar algunas características personales que se repetían en la mayoría de los emprendimientos exitosos de todo el mundo que analizaron, y las cuales actúan como competencias que son inherentes a cada emprendedor. Existe una relación entre competencias, aptitudes y rasgos de personalidad, pero con un importante matiz: las competencias son algo más que características individuales, ya que también hacen alusión a los conocimientos adquiridos por los sujetos a través de la experiencia [5]. Parte del cambio de paradigma radica en que el aumento de la productividad no se refiere únicamente al acceso a tecnología de punta y a la conformación de equipos de trabajo; se apoya, sobre todo, en nuevas formas de organización y de gestión, las cuales conjuntamente con la formación continua alientan el uso eficiente de los recursos y estimulan el potencial creativo de los miembros del equipo de trabajo. Una de las características principales de estas competencias es que sólo se perciben en la 
acción. Hablamos de competencia cuando logramos movilizar y poner en marcha estas capacidades.

Una de estas competencias emprendedoras es la identificación de oportunidades. Oportunidad significa estar en el lugar, a la hora y con la actitud necesaria, con el fin de aprovechar en buena forma la oportunidad de negocio que el mercado brinda. El emprendedor es una persona que se distingue del resto por el simple hecho de que vive enfocado en las oportunidades, sabiendo pasar de la etapa de inspiración a la de transpiración para dar origen a su empresa. Evitando imponer cuales son estas oportunidades - ya que nadie mejor que el emprendedor para poder identificarlas-, con la presentación de las cadenas productivas se busca acercar un aporte de una forma de leer la economía local, lo cual le permita al emprendedor tener un conocimiento más cercano de las actividades productivas que se llevan a cabo en una localidad y, si él lo considera, estar en capacidad de identificar nichos de negocios.

\section{Búsqueda e identificación de oportunidades}

Una idea o una invención no son necesariamente una oportunidad. Para que una idea se convierta en una oportunidad comercial exitosa debe aprobar ciertos criterios básicos de validación. Pero si idea y oportunidad coinciden, la creación de una empresa puede ser viable. Con el fin de saber si la idea emprendedora es una oportunidad de negocio, es necesario escuchar atentamente el mercado, testarlo y tener en cuenta además otras variables como la existencia o no de una demanda suficiente y la posibilidad de disponer de recursos. Es importante tener en claro esto: la buena idea es solamente el primer paso en la tarea de convertir la creatividad del emprendedor en una oportunidad real. Una idea es una oportunidad solamente cuando puede ser implementada, cuando agrega valor al comprador final o cuando se encuentra una predisposición a pagar por ese producto más que su costo, entre otras consideraciones. Podemos decir a grandes rasgos que la creación de empresas depende de la suma de la actitud más la implementación de un proceso, focalizados en el aprovechamiento de una oportunidad.

Las oportunidades existen porque los gustos y las costumbres cambian y porque se generan nuevos conocimientos. Estas oportunidades pueden surgir a partir de problemas (¿es posible desarrollar un emprendimiento que solucione problemas?); cambios (¿qué cambios están ocurriendo en el entorno que puedan transformarse en una oportunidad?); invenciones (aunque uno no inventa algo, ¿es posible encontrar una manera creativa de venderlo a nuevos clientes?); competidores (¿puedo hacerlo yo mejor que las actuales empresas, más rápido, más barato, más útil?), etc. Pueden ser oportunidades el desarrollo de nuevos productos o servicios, la implementación de nuevos métodos productivos, la introducción de nuevos canales de distribución, el diseño de nuevas estrategias comerciales, los nuevos mercados o las nuevas maneras de proveer.

La viabilidad de un negocio depende de su permanente adecuación a las necesidades del mercado. Es necesario, por tanto, saber hacia dónde se dirige la demanda de los consumidores con el fin de identificar una oportunidad de negocio con futuro. Valorar si se contará con demanda suficiente, si el mercado lo necesita, si no está saturado ya con la oferta actual, o si el futuro negocio tendrá clientes. La evaluación de la idea de negocio debe asociarse primero con un análisis cualitativo del negocio, en el cual está tratándose de revisar la existencia o no de ciertos de sus elementos básicos. La respuesta honesta a estas preguntas básicas permite saber si se está o no ante una simple idea o ante una verdadera oportunidad. Este proceso permitirá definir mejor la oportunidad o identificar oportunidades complementarias o adicionales. En muchas ocasiones, un negocio empieza con una oportunidad dada, pero en su desarrollo se identifica otra oportunidad y es esta segunda la que trae el éxito. El empresario, una vez inicia su actividad empresarial, va encontrando nuevas puertas y nuevos caminos que le permiten reorientar, diversificar o complementar sus oportunidades de negocio. La oportunidad tiene que ser apropiada, coincidente con los gustos, deseos, necesidades, expectativas y capacidades de mercado.

\section{La importancia del entorno productivo}

El territorio no es tan sólo un marco de la economía sino un recurso económico. En este sentido, es la calidad del territorio la que le permite a una tecnología entrecruzarse con una cultura; a las empresas, encontrar un ambiente propicio; al mercado, traducir la competencia en cooperación, y a la economía 
en su conjunto, movilizar a la sociedad y las intenciones de cada uno de sus miembros. Se toma al territorio como un agente de transformación y no como un mero soporte de los recursos y actividades económicas, ya que las empresas y los demás actores del territorio interactúan entre sí organizándose para desarrollar la economía y la sociedad. Son precisamente las Pymes y las nuevas empresas con su capacidad empresarial y organizativa las que están llamadas a tener un papel protagonista en el desarrollo endógeno. Las propuestas de los estudiosos de los procesos de industrialización endógena y de industrialización en áreas rurales surgen como reacción del agotamiento del modelo de desarrollo basado en la localización de grandes empresas en grandes ciudades, y muestra cómo el desarrollo de muchas regiones del mundo se basó en sistemas productivos locales y en activas políticas de creación de empresas.

La dinámica del nuevo orden global parece empujar a esta búsqueda de articulación de lo local como única alternativa para el desarrollo. Por un lado, las empresas están objetivamente condicionadas a cooperar entre ellas debido a la forma de especialización que ha ido adoptando un sistema productivo, y a que su reducida dimensión fuerza a la cooperación, con el fin de obtener las economías de escala que son necesarias para competir. Además, las estructuras familiares, las tradiciones locales, los valores sociales y culturales, y los códigos de la población favorecen la dinámica de desarrollo, aportan recursos humanos y financieros, facilitan las relaciones laborales y sociales, y favorecen los intercambios de bienes y servicios, formales e informales, así como la difusión de la información y el conocimiento de la red de empresas y las relaciones locales. El sistema de relaciones y de conexiones entre las empresas que se ha ido creando históricamente forma parte de la cultura social y productiva de la comunidad local, y toma formas diferentes en cada localidad.

Un distrito industrial es una organización de la producción que conforma un conglomerado de empresas conectadas geográficamente y especializadas sectorialmente. Al mismo tiempo forman un encadenamiento hacia delante y hacia atrás, entre diferentes agentes económicos basado en el intercambio de bienes, información y personas, a través de los mercados o fuera de ellos. Las relaciones de los agentes económicos obedecen a un código de conducta, resultado del medio social y la cultura predominante.
Sinónimo de esto son expresiones tales como complejos industriales, conglomerados, aglomerados y economías de localización.

Un clúster es un grupo geográficamente denso de empresas e instituciones conexas, pertenecientes a un campo tecnológico concreto, unidas por rasgos comunes y complementarias entre sí. Por su dimensión geográfica, un clúster puede ser urbano, regional, nacional o incluso supranacional. Estos clúster adaptan varias formas dependiendo de su especificación y complejidad, pero la mayoría de ellos comprenden empresas de productos o servicios afines. También suelen integrar empresas que constituyen eslabones posteriores de la cadena (es decir, canales de distribución o clientes), fabricantes de productos complementarios, proveedores de infraestructuras, instituciones públicas y privadas que facilitan formación, información, investigación y apoyo técnico (universidades, centros de investigación, consultoras), e instituciones de normalización. Igualmente, los organismos públicos que participan pueden sentirse parte de él. Como reflexionan los estudios de localización posteriores a Marshall [6], tales como Feldman y Austredch [7]. La sola agrupación de empresas no da por sí sola origen a un clúster. El secreto está en la interacción: si se desarrolla un sistema de preferencias que incite a los miembros de la comunidad a elegir a otros integrantes, puede empezar a hablarse de clúster. Este proceso de selección puede darse entre empresas que se ocupan de fases sucesivas de un determinado proceso (colaboración vertical), así como también entre empresas que compiten entre sí (colaboración horizontal). Esto sucede gracias a una mayor permeabilidad entre los agentes componentes y la fluidez de las relaciones entre ellos.

Existen muchas definiciones que se refieren a los distritos industriales, los conglomerados y la relación de los diversos actores para la producción de diversos bienes con valor agregado. Cadenas, diversos clúster, distritos, etc., conforman un abanico conceptual aportado primero desde la geografía económica, y luego por otras escuelas económicas más jóvenes tales como las teorías de desarrollo local, evolucionista del cambio tecnológico, economía institucionalista, etc. Si bien las distinciones generan un aporte importante, con el fin de simplificar el análisis, este artículo se referirá a cadenas productivas en un sentido más amplio, sin tener en cuenta otras especificaciones. 


\section{Cadenas productivas}

Una cadena productiva es el conjunto de agentes y actividades económicas que intervienen en un proceso productivo, desde la provisión de insumos y materias primas, su transformación y producción de bienes intermedios y finales, hasta su comercialización en los mercados internos y externos, incluyendo proveedores de servicios, sector público, instituciones de asistencia técnica y organismos de financiamiento.

Las principales ventajas de integración en una cadena productiva son:

- El fortalecimiento de las instituciones participantes en los acuerdos.

- Mayor rentabilidad en la producción obteniendo mejores precios y reduciendo los costos.

- Disminución del riesgo.

- Facilidad en el acceso a los insumos.

- Acceso a fuentes de financiamiento, créditos y economías de escala.

- Acceso a información de mercados.

- Mayor acceso a tecnología de punta.

- Mejor aprovechamiento de la mano de obra familiar.

Una cadena productiva está conformada por una secuencia de eslabones en la cual operan actores económicos que centran sus actividades en la producción de un producto o servicio. Un eslabón de la cadena está conformado por un grupo de actores económicos que realizan actividades similares, tienen procesos de generación de valor similar, poseen derechos propietarios sobre un producto o servicio en un estado de valor definido, transfieren ese mismo producto a los mismos clientes y reciben insumos de los mismos proveedores. También es una bolsa de mano de obra especializada y de conocimientos técnicos sobre las distintas funciones y procesos asociados con el producto principal, ya sean zapatos, muebles, vestidos u otra cosa. Los conocimientos técnicos generales pueden transmitirse a través de la comunidad local, de padres a hijos y de compañero a compañero, de forma que constituyan un legado cultural permanente de la zona. Igualmente, estos conocimientos pueden impartirse en las escuelas técnicas u oficios. También las universidades y los centros de investigación pueden ocupar un papel predominante en la creación de conocimientos especializados y de mano de obra cualificada.

Las empresas de estos conglomerados las podemos clasificar en tres categorías: ensambladoras, monofase y relacionadas. Hasta un treinta por ciento de las empresas de una cadena suelen tener acceso al mercado final. Se trata básicamente de empresas ensambladoras de productos. Las llamadas empresas monofase sólo intervienen en una fase intermedia de la producción. Por ejemplo, en la cadena productiva textil, las empresas monofase se ocupan o bien del cosido, o bien de la mallería o del tejido, entre otras actividades especializadas. Las empresas relacionadas no se clasifican estadísticamente dentro del sector industrial al que se asocia el clúster. Por ejemplo, en la cadena productiva textil hay empresas que fabrican botones y que estadísticamente pueden pertenecer al sector químico, empresas que pertenecen al sector de servicios (como las de leasing o banca), y empresas que se ocupan del transporte. Cada una de las empresas tiende a especializarse en una sola o en unas pocas fases de los procesos de producción típicos de la cadena, dejando a las claras las características de proceso de división del trabajo localizado en una zona, el cual ni se diluye en el mercado general ni se concentra en una empresa o en unas pocas empresas.

En relación con la aparente antinomia entre industria y servicios que ha dado lugar a muchos debates, debe notarse que hoy su límite se ha vuelto bastante impreciso. Por un lado, en la actividad industrial actual un componente importante del valor agregado está constituido por servicios. Por otra parte, en forma creciente la industria recurre a la externalización, lo cual implica subcontratar trabajo a empresas o a personas con el fin de atender actividades subsidiarias tales como las de mantenimiento, limpieza, catering o mensajería, o para hacer frente a la necesidad de habilidades específicas que el personal de la empresa no posee, como podrían ser el procesamiento de datos o el análisis de sistemas. Esta forma de organización de la actividad industrial se registra estadísticamente como un desplazamiento de la industria por los servicios. 


\section{Las cadenas productivas en el sector rural}

El sector de agronegocios no puede dar cuenta solamente de lo que pasa tranqueras adentro, de la dinámica económica de la producción de alimentos. En el proceso productivo, surgen nuevas etapas y distintos agentes. Estos influyen e incluso determinan la dinámica conjunta de todo el proceso productivo, el cual se inicia en el final de la cadena, es decir, en el consumidor, para terminar llegando al principio, es decir, al campo. Y a lo largo de la cadena se extienden todo tipo de conexiones horizontales. Ya se ven redes empresariales en las que unos poseen tierras, otros dan parte de los servicios y otros más grandes, integrados verticalmente, desarrollan la cadena hacia la entrega final del cliente [8].

Hoy en día, la población se alimenta y satisface la mayoría de sus necesidades merced a la acción de un conjunto heterogéneo de agentes que operan en las distintas etapas. Un vasto complejo de empresas y operadores engloba la producción, distribución y el consumo de alimentos y otros productos agrícolas. Dentro de este complejo, operan distintos agentes económicos que actúan en las diferentes etapas productivas, comerciales, de servicios, transporte y distribución. Estos agentes operan en un espacio propio, en el cual imperan ciertas instituciones, dentro de un ambiente jurídico y organizacional determinado.

El contexto competitivo lleva a la necesidad de generar nuevos modelos organizativos empresariales, entre los que merecen destacarse los procesos de desverticalización y redireccionamiento de las grandes empresas hacia las etapas centrales de la firma, mediante la terciarización de sus actividades secundarias. Al mismo tiempo, toman importancia formas de coordinación más estrechas, tanto verticales (relaciones cliente/proveedor entre la agricultura, la industria y la distribución), como horizontales (asociaciones entre empresas para fines tecnológicos, productivos o comerciales).

La observación de la importancia en la actividad económica de las cadenas productivas puede corroborarse al analizar la economía de una provincia argentina. Por ejemplo, 29 cadenas productivas en Mendoza acumulan las tres cuartas partes de la producción de bienes (aquí incluimos el turismo también), y traccionan prácticamente toda la producción del sector agropecuario. Por estas razones, es posible afirmar que el proceso de detección y análisis de oportunidades de negocios en el sector rural encuentra un decisivo punto de apoyo en el análisis de las cadenas productivas que operan en cada territorio.

Los servicios revelan los cambios que el campo argentino viene experimentando, con un importante rol pocas veces considerado. La influencia de los prestadores de servicios es predominante en nuestro país, y en la alta productividad que ha alcanzado el sector agropecuario argentino. El prestador de servicios agropecuarios abarca actividades tales como: (a) servicios de maquinarias agrícola (servicios de labranza y labores complementarias de preparación de suelo; siembra y trasplante; cuidados culturales mecánicos y químicos, servicios de cosecha, etc.); (b) servicios de mano de obra agrícola; (c) servicios de inseminación artificial y servicios para mejorar la calidad de los animales; (d) servicio de contratista de mano de obra pecuaria y (e) otros servicios pecuarios.

Los productores, proveedores de servicios o industriales agregan valor adicional a cada una de estas etapas de una cadena productiva. Un ejemplo sencillo sería el de la cadena de valor de alguna fruta en fresco, la uva por ejemplo, es posible encontrar a los productores vitícolas, los cuales venden uva a los galpones de empaque, a la vez que compran insumos como plantines y agroquímicos, o servicios como las tareas culturales de poda o cosecha. Los empaques tienen capacidades de acondicionamiento adecuadas a las demandas del tipo de mercado que atiendan, con túneles de preenfriado si exportan o frigoríficos más sencillos si venden en el país, y también subcontratan servicios de transportistas, de reparación de equipos $u$ otros, $y$ venden uva en fresco en grandes mercados de abasto, o a traders o a supermercados. Todos estos actores económicos forman parte de la cadena de valor. Algunos de ellos se encuentran en el ámbito local o provincial (productores, servicios, insumos, empaques, etc.), y otros más lejanos.

\section{1 ¿Por qué utilizar un enfoque de cadenas productivas en el sector rural?}

La gran mayoría de los nuevos negocios que se desarrollan en el ámbito rural atienden demandas y necesidades de otras unidades económicas, venden la mayor parte de sus productos o servicios a otras empresas y no a los consumidores finales. 
El análisis convencional pretendía, a través de una visión fragmentaria y centrada en los sectores horizontales, entender el mundo de los negocios agrícolas y su contexto. Esta visión solía hablar, por ejemplo, de la producción agraria como un fenómeno que nace y muere en el establecimiento rural. Se trata de una visión de fuerte arraigo en Argentina que poco tiene que ver con la realidad. Esta visión desde el producto explica en gran parte la invisibilidad de los servicios en el sector agropecuario. Si bien comienzan a emerger industrias de servicios de valor agregado para la actividad, fundamentalmente a partir del avance de las nuevas tecnologías y las mejoras de los sistemas de producción, estos suelen concentrarse en las zonas de mayor desarrollo y mayores recursos. Como el grado de conocimiento por fuera de la actividad productiva que se conoce y que históricamente se desarrolló es relativamente bajo, el productor suele sentirse más seguro.

Entre el mercado y la integración vertical, los sistemas agroindustriales trabajan dentro de un conjunto universal de formas intermedias, como la cuasi integración vertical de proveedores, redes de empresas independientes, alianzas estratégicas, etc.

Los sectores económicos más desarrollados atienden demandas más o menos remotas, y para ello normalmente el proceso técnico y comercial completo se subdivide y resulta realizado por diferentes actores especializados en cada una de las etapas: el productor primario, los proveedores de servicios e insumos, los transformadores e industrializadores, los transportistas, los vendedores en los grandes mercados, etc.

Este análisis facilita la valoración del potencial económico de las ideas de negocios, o sugieren nuevas ideas allí donde observen necesidades o problemas factibles de ser resueltos por actores locales. El análisis de las cadenas es un análisis concreto de las demandas potenciales de más fácil accesibilidad para los emprendedores locales, de los clientes con nombre y apellido, del reconocimiento de magnitud potencial de facturación de un nuevo negocio, del tipo de barreras a la entrada de nuevos emprendimientos que se pueden enfrentar, etc. El análisis de las cadenas productivas que operan en el territorio es un buen punto de partida para el programa emprendedor, evitando las difusas nociones de estudios "del mercado" como un ente impersonal y abstracto.
Además de la existencia de cadenas productivas, o al menos de una relevante aglomeración de unidades productivas en algunas de las fases, es un indicador de la existencia de una gran cantidad de activos vinculados a este tipo de actividades económicas en la región (mano de obra especializada, conocimientos técnicos específicos, información de los mercados o demandas, relaciones personales entre los actores). Estos hechos harán aún más fácil la concreción de oportunidades de negocios, ya que bajan significativamente algunas barreras de entrada que deberían enfrentar los emprendedores.

Las dificultades para ver las oportunidades suelen relacionarse con barreras que impiden ver las cosas desde una perspectiva distinta. Centrarse solamente en la actividad productiva que uno sabe hacer, y pensar que la actividad productiva nace y muere tranqueras adentro, es una visión de fuerte arraigo en Argentina que poco tiene que ver con la realidad. Enfrentarse contra esta visión es hacerlo contra un verdadero paradigma que lleva años instalado, pero ser emprendedor también radica en conocer la realidad y operar sobre ella.

\subsection{Un aporte metodológico: ¿cómo analizar las cadenas productivas de mi región?}

La tradición de saberes en el ámbito rural — generalmente ligada al conocimiento técnico de producción y limitada al conocimiento del producto-obliga a un trabajo especial que propicie el análisis de las cadenas productivas y su posible identificación como fuente de oportunidades para emprendedores. A continuación se propone un esquema de trabajo que puede ser utilizado en los programas de capacitación para emprendedores, así como por los facilitadores/tutores de los programas de creación de empresas, encargados de la atención directa y el asesoramiento a los emprendedores, enmarcados en lo que, según Varela [9], Wilkinson [10] y Kuratko [11], podemos denominar un enfoque en competencias.

Con el fin de analizar las cadenas productivas, sugerimos responder a las siguientes preguntas:

1. Para cada producto primario, ¿cuáles son las sucesivas etapas de transformación que se le realizan? Desarrollar gráficamente de modo completo el ciclo de transformaciones (figura 1). 


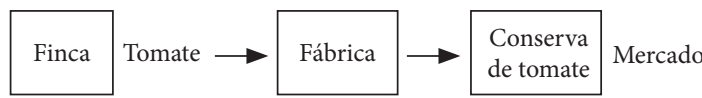

Figura 1. Esquematizar todas las secuencias productivas básicas de cada cadena

Fuente: elaboración propia

2. Observar para cada una los servicios o productos de terceros que compran, localmente o en otras provincias, del mismo modo que se observa en el anterior gráfico de la conserva de tomate.

3. Agrupar estas cadenas por negocios comunes, utilizando el listado de negocios que se presenta más abajo, esto es, la venta de peras en fresco o manzanas en fresco se realiza en ambos casos a través de galpones de empaque, y por ello los dos cultivos participan del mismo negocio de la fruta en fresco. Ahora, el productor puede venderle otra parte u otra calidad del mismo producto a los fabricantes de conservas y, por lo tanto, atender a más de una cadena, y este hecho nos permitirá identificar la existencia de otra cadena productiva, u otro negocio.

4. Finalmente, reunir todas las cadenas en un cuadro, en principio con al menos la información que se presenta en la tabla 1.

Tabla 1. Identificación de actores en una cadena productiva

\begin{tabular}{|c|c|c|}
\hline $\begin{array}{c}\text { Cadena productiva } \\
\text { Negocio }\end{array}$ & $\begin{array}{c}\text { Actores } \\
\text { Principales }\end{array}$ & $\begin{array}{c}\text { Servicios } \\
\text { (indicativa no } \\
\text { exhaustiva) }\end{array}$ \\
\hline $\begin{array}{l}\text { Fruta/Hortaliza en } \\
\text { fresco: } \\
\text { negocio orientado } \\
\text { a conseguir proveer } \\
\text { productos frescos en } \\
\text { los mercado finales } \\
\text { remotos. }\end{array}$ & $\begin{array}{l}\text { Empaques } \\
\text { Productor } \\
\text { primarios }\end{array}$ & $\begin{array}{l}\text { Frío } \\
\text { Cosecha } \\
\text { Tareas culturales } \\
\text { Riego } \\
\text { Sanidad } \\
\text { Técnicos } \\
\text { Agronómicos }\end{array}$ \\
\hline $\begin{array}{l}\text { Concentrados: } \\
\text { negocio orientado } \\
\text { a vender a clientes } \\
\text { industriales pulpas } \\
\text { concentradas de frutas } \\
\text { u hortalizas. }\end{array}$ & $\begin{array}{l}\text { Fábricas de } \\
\text { concentrado } \\
\text { Productores } \\
\text { primarios }\end{array}$ & $\begin{array}{l}\text { Equipos } \\
\text { industriales de } \\
\text { concentrado } \\
\text { Equipos de } \\
\text { pasteurización } \\
\text { Servicios } \\
\text { metalmecánicos }\end{array}$ \\
\hline Vinos & $\begin{array}{l}\text { Bodegas } \\
\text { Fraccionadoras } \\
\text { Bodegas } \\
\text { Trasladistas } \\
\text { Productores } \\
\text { Vitícolas }\end{array}$ & $\begin{array}{l}\text { Bombas de } \\
\text { remontaje } \\
\text { Filtros } \\
\text { Corchos } \\
\text { Capsulas }\end{array}$ \\
\hline
\end{tabular}

\begin{tabular}{|c|c|c|}
\hline $\begin{array}{c}\text { Cadena productiva } \\
\text { Negocio }\end{array}$ & $\begin{array}{c}\text { Actores } \\
\text { Principales }\end{array}$ & $\begin{array}{c}\text { Servicios } \\
\text { (indicativa no } \\
\text { exhaustiva) }\end{array}$ \\
\hline $\begin{array}{l}\text { Turismo rural: } \\
\text { atender turistas } \\
\text { que disfrutan de } \\
\text { las tradiciones } \\
\text { productivas y } \\
\text { culturales, la vida y los } \\
\text { atractivos de las zonas } \\
\text { rurales. }\end{array}$ & $\begin{array}{l}\text { Operadores } \\
\text { turísticos } \\
\text { Fincas y } \\
\text { residencias rurales }\end{array}$ & $\begin{array}{l}\text { Agencias de viaje } \\
\text { Empresas de } \\
\text { transporte } \\
\text { Remises y taxis }\end{array}$ \\
\hline
\end{tabular}

Fuente: [12]

5. Delimitar cuáles de los actores de la cadena se encuentran dentro del territorio, y cuáles no.

6. Obtener la mayor cantidad de información disponible sobre cada una de las cadenas productivas existentes (facturación total de la cadena, cantidad de productores primarios existentes en la región, otras regiones competidoras, exportaciones, canales de comercialización, logística, etc.).

\section{Conclusiones}

El aporte de una visión de cadenas productivas a un proceso de desarrollo emprendedor genera múltiples ventajas, entre ellas:

- Permite conocer cada dimensión de la actividad económica de las localidades e identificar oportunidades a partir de estas.

- Brinda la posibilidad de conocer con nombre y apellido a los productores y empresas que se desempeñen en un determinado sector.

- Permite identificar determinados productos o servicios que alimentan la cadena que se pueden estar aportando desde fuera de mi localidad.

- Puede llegar a generar un importante interés por parte del resto de empresas que integran la cadena, con el fin de que se desarrollen determinados emprendimientos en la localidad que fortalezcan su propia actividad económica.

- Favorece la identificación de oportunidades en el sector servicios. En el ámbito rural, no suelen pensarse tantos emprendimientos de este tipo, en comparación con la elaboración de productos.

- Fortalece la identificación de las redes como otra característica emprendedora personal fundamental para la creación de empresas. 
- Ayuda en la planificación de los emprendimientos, ya que obliga a desarrollar un verdadero estudio de mercado del sector.

- Permite aproximarse a un análisis de riesgo más detallado, ya que está íntimamente relacionado con los patrones productivos de la localidad.

El análisis de cadenas productivas locales encaminadas a la identificación de oportunidades es una actividad que no sólo debe llevarse a cabo en las jornadas de capacitación para emprendedores. El tutor/ facilitador de los programas tiene un rol central en esta actividad, haciendo las preguntas adecuadas y facilitando las redes de apoyo para que los emprendedores diseñen su propio mapa de encadenamiento productivo. Una buena planificación tiene que contar con buena información. Si hay cosas que influyen en la actividad de la cadena productiva, pero que no se conocen y no se han tenido en cuenta al hacer el plan, puede ser que el proyecto fracase. La actitud de estar atento, con las "antenas paradas", en actitud de escucha permanente, ávido de conocer cosas que sirvan al proyecto, aumentará las posibilidades de éxito de los emprendimientos. Las relaciones de negocio requieren de una ampliación del concepto de redes, y es necesario desarrollar redes de información, de vinculación, de interés práctico. El establecimiento de un entramado de relaciones que van desde las simples relaciones con amigos y conocidos, hasta las alianzas con otros empresarios del mismo sector o de otros relacionados, incluyendo conexiones con instituciones y organizaciones públicas y privadas, es un aspecto indispensable para el éxito de un emprendimiento y para pensar las oportunidades dentro de las cadenas productivas.

Pensar en cadenas también ayuda a pensar en sistemas productivos locales, en la articulación de empresas proveedoras, de servicios y de diferentes ramas productivas, con los centros de investigación e instituciones educativas y el apoyo del sector público a partir de su marco legal y los programas de promoción en la creación de empresas. La capacidad de desarrollar en una misma localidad los eslabones de las cadenas que están faltando es un importante desafío de cara al desarrollo y un significativo nicho de oportunidades para los emprendedores.

\section{Referencias}

[1] H. Kantis, Emprendedores de origen humilde: ¿cómo incide la estructura social en la creación de empresas en América Latina? Buenos Aires: Univ. Nac. de General Sarmiento, 2004. [En línea]. Disponible en: http://www.littec.ungs.edu.ar/pdfespa\%F1ol/ DT\%2010-2005\%20Kantis.pdf

[2] A. Etzioni, Entrepeneurship, adaptation and legitimation. A Macro behavioral Perspective, Washington, DC: George Washington Univ., 1986. [En línea]. Disponible en: http://www2.gwu.edu/ ccps/ etzioni/A181.pdf

[3] P. H. Thornton, The Sociology of Entrepeneurship. Durham, North Carolina: Duke University, 1999. [En línea]. Disponible en: http://www.annualreviews.org/doi/abs/ 10.1146/annurev.soc.25.1.19

[4] D. C. McClelland, "Testing for competence rather than intelligence", American Psychologist, vol. 1, n. ${ }^{\circ}$ 28, pp. 1-14, 1973. [En línea]. Disponible en: http:// psycnet.apa.org/psycinfo/1973-22126-001

[5] M. Martínez y G. Carmona, "Aproximación al concepto de competencias emprendedoras: Valor social e implicaciones educativas", REICE, vol. 7, n. ${ }^{\circ}$ 3, 2009. [En línea]. Disponible en: http://www.rinace.net/reice/numeros/arts/vol7num3/art6.pdf

[6] A. Marshall, Principles of Economics, Macmillan and Company, 1890. [En línea]. Disponible en: www. oei.es/noticias/spip.php/inicialbbva/material/spip. php?article5802\&debut5ultimasOEI=5

[7] M. Feldman y D. Audretch, "Innovation in Cities: Science Based Diversity, Specialization and Localized Competition", European Economic Review, vol. 43, pp. 409-429, 1997. [En línea]. Disponible en: www.oei.es/noticias/spip.php/inicialbbva/material/ spip.php?article5802\&debut_5ultimasOEI=5

[8] M. Alvarado Ledesma, Agronegocios. Empresa y emprendimiento. Argentina: El Ateneo, 2006.

[9] R. Varela, A. O. L. Bedoya, "Modelo conceptual de desarrollo empresarial basado en competencias", en Estudios Gerenciales. Bogotá: 2006. [En línea]. Disponible en: http://www.icesi.edu.co/revistas/index. php/estudios_gerenciales/article/view/198/html

[10] A. Wilkinson, The Creator's Code: The Six Essential Skills of Extraordinary Entrepreneurs. New York: Simon \& Schuster, 2015.

[11] D. F. Kuratko, J. S. Hornsby y M. G. Goldsby, Innovation acceleration: "Transforming organizational thinking". Pearson Higher Ed., 2011. [En línea]. Disponible en: https://estebancampero.wordpress. com/2014/11/14/por-que-el-proyecto-jovenes-emprendedores-rurales-es-el-programa-mas-completo-de-argentina/ 